\title{
Anatomical and biomechanical evaluation of the tension band technique in patellar fractures
}

\author{
Onder Baran • Metin Manisali • Berivan Cecen
}

Received: 17 April 2008 /Revised: 7 May 2008 / Accepted: 13 May 2008 / Published online: 11 July 2008

(C) The Author(s) 2008

\begin{abstract}
Tension band wiring for patellar fractures is common, but some recent reports refer to disadvantages of this approach. Our anatomical and biomechanical study focused on use of tension band techniques in patellar fractures. The anatomy of the patella and tendon insertion was examined with knee magnetic resonance imaging (MRI) and correlated with the technical requirements of the tension band. Tension band wiring over tendinous tissue was simulated and calculated with a cyclic biomechanical test on cow patellae. According to tension band templating on the MRI section, Kirschner wire insertion was needed for the tension band to turn over the tendinous tissue. The tension band became more stable while turning over less tendinous tissue and more adjacent bone surface. Nevertheless, cyclic loading tests indicate that all tension band applications in this study lose their initial stability. Excessive initial compression by the tension band resulted in bending of the Kirschner wire and thus reduction failure. For optimum stabilisation, tension force transfer should be done directly on bone or at least material that protects the tendon would be useful.
\end{abstract}

\footnotetext{
O. Baran $(\bowtie)$

Department of Orthopedics and Traumatology,

Dokuz Eylul University,

35340 Izmir, Turkey

e-mail: onder.baran@deu.edu.tr

O. Baran · B. Cecen

Department of Biomechanics, Health Sciences Institute,

Dokuz Eylul University,

35340 Izmir, Turkey

M. Manisali

Department of Radiology, Dokuz Eylul University,

35340 Izmir, Turkey
}

Résumé La tension des fils métalliques lors de l'ostéosynthèse par hauban des fractures de rotules est habituellement utilisée, mais certains travaux en montrent les désavantages. Cette étude anatomique et biomécanique a été centrée sur cette pratique du hauban dans les fractures de la rotule. L'anatomie de la rotule et des insertions tendineuses ont été étudiées et corrélées avec les nécessités de tension. La tension de ce hauban mis en place au dessus des structures tendineuses a été évaluée par des tests biomécaniques sur des rotules de vaches. Selon l'insertion des broches de Kirschner, après étude IRM, il est nécessaire de serrer les fils du hauban sur les structures tendineuses mais, ce hauban est beaucoup plus stable que les tissus tendineux adjacents à l'os. Cependant, les tests de mise en charge nous montrent que ces haubans perdent leur stabilité initiale dès qu'une tension importante entraîne une plicature des broches de Kirschner et un échec de la réduction. Pour une stabilisation optimum, les forces de serrage du hauban doivent être directement appliquées sur l'os ou, tout au plus, au niveau de l'insertion tendineuse au plus près du matériel.

\section{Introduction}

The tension band technique is mostly used in patellar fractures. There are some recent reports indicating a high failure rate $(50 \%)$ of the modified tension band technique despite previous good results. Several modifications have been used to increase the stabilisation of the tension band technique along with other techniques [4, 7, 9].

Although difficulties concerning the modified tension band technique are described and defined in textbooks and the literature in detail, technical inadequacies are often underestimated. This study aimed to explore the relationship between patellar anatomy, tension band and Kirschner 
wiring. Although the tension band is the main factor in achieving stability, Kirschner wiring designates tension band projection on tendon and bone. First of all, we explored this relationship with a magnetic resonance imaging (MRI) study. With the data obtained, technical requirements and anatomical and dynamic specifications were tested and assessed.

\section{Material and methods}

\section{Anatomical study}

Patellar variation was evaluated with knee MRI studies. Sagittal sections of patellae that pass the thickest point were obtained from 30 knee MRI studies; patellar diameter, tendon insertion, localisation and thickness were measured (Fig. 1).

The modified tension band technique was used according to the AO Manual of Internal Fixation. Templating the tension band technique was performed on MRI (Kirschner wire drawn 5-6 $\mathrm{mm}$ posteriorly from the anterior surface of the patella) (Fig. 2). Kirschner wiring position in relation to tendinous tissue was evaluated with three parameters: outside-anterior (A), inside-median (M) and outside-posterior $(\mathrm{P})$.

\section{Biomechanical study}

Seven cow patellae with tendinous tissue were used as biomechanical test material. Cow patellae were cut trans-

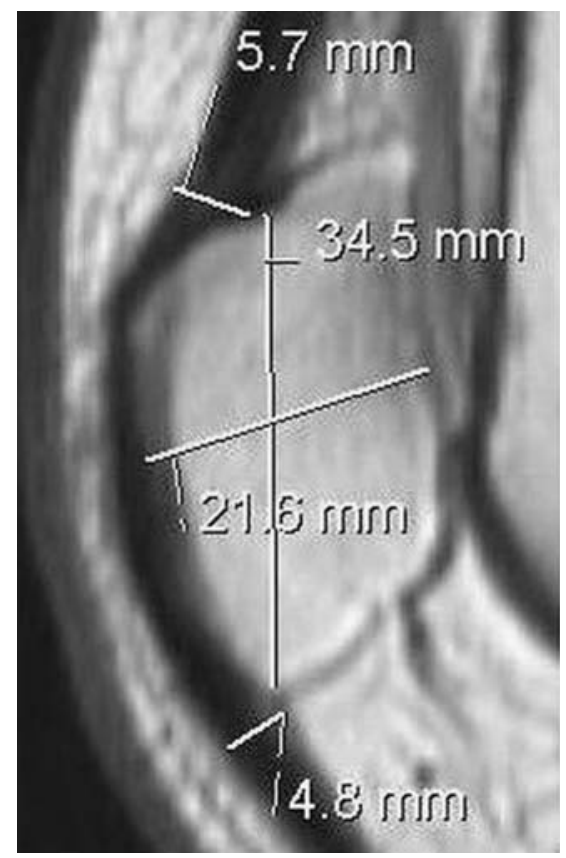

Fig. 1 Patellar section of MRI

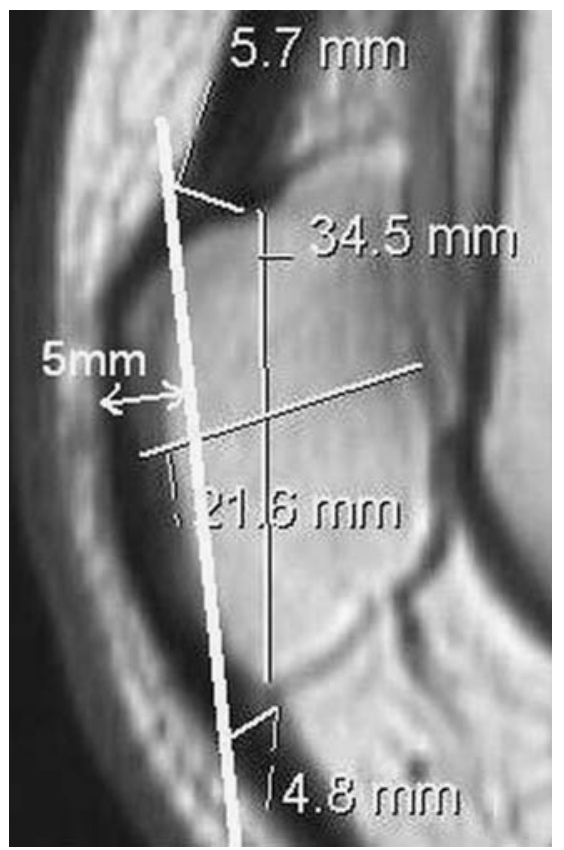

Fig. 2 Kirschner wire templating on MRI section

versely $2 \mathrm{~cm}$ from the pole to simulate human patellar fractures. Prepared cow patellar fragments were fixed on a traction apparatus by two 2-mm Kirschner wires, which passed $5 \mathrm{~mm}$ posteriorly from the anterior surface of the patella and through tendinous tissue. With a $1.2-\mathrm{mm}$ tension band wire, four configurations were simulated: vertically oriented figure-of-eight passed anteriorly to the tendon (a), horizontally oriented figure-of-eight (b), vertically oriented figure-of-eight passed posteriorly to the tendon (c) and to eliminate the effect of the tendon a control group (d) was established as vertically oriented figure-of-eight without tendinous tissue. Figure 3 shows these orientations.

Distractions on the tension band wire were performed by a compression-distraction test device (AG-I $10 \mathrm{kN}$, Shimadzu, Kyoto, Japan) with $3 \mathrm{~mm} / \mathrm{min}$ traction speed to a maximum load of $200 \mathrm{~N}$ and then ten cyclic loadings were performed between 100 and $200 \mathrm{~N}$ (Fig. 4).

The data on force-displacement variation were evaluated with the Kruskal-Wallis test using SPSS 11.0 for Windows. Statistical analyses were performed using a Mann-Whitney $\mathrm{U}$ test to estimate group differences.

\section{Results}

Knee MRI sagittal sections of 30 patients were obtained and evaluated. Patellar size measurements were taken with the following findings: mean patellar lengthening $34 \pm$ $3 \mathrm{~mm}(30.6-42.9 \mathrm{~mm})$, mean patellar thickness $19.6 \pm$ $2.3 \mathrm{~mm}(15.5-26.1 \mathrm{~mm})$, mean patellar tendon insertion 


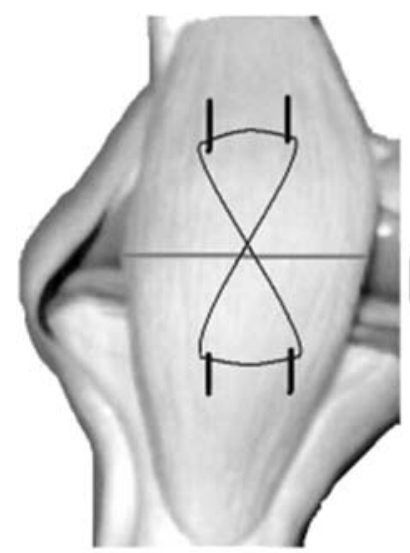

a

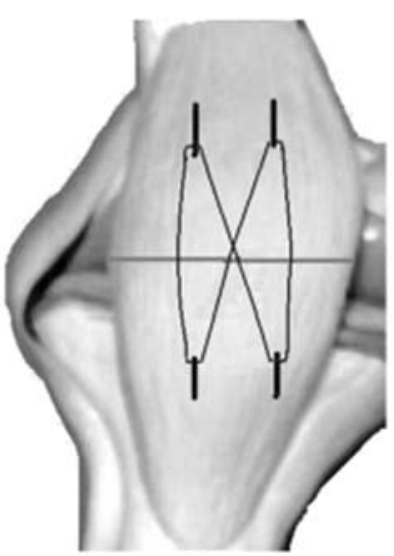

b

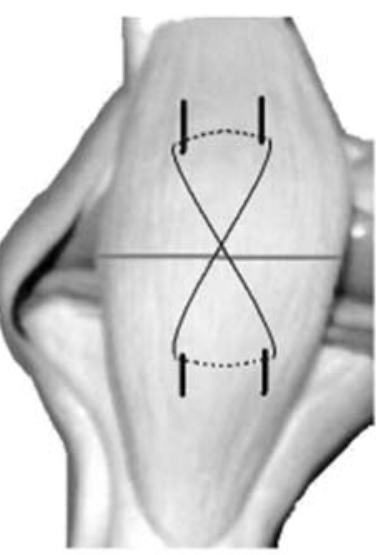

C

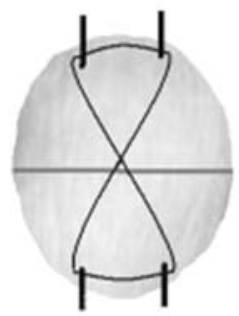

d
Fig. 3 Tension band configurations are vertically oriented figure-ofeight passed anteriorly to the tendon (a), horizontally oriented figureof-eight (b), vertically oriented figure-of-eight passed posteriorly to

thickness $4.8 \pm 1 \mathrm{~mm}(3-6.8 \mathrm{~mm})$ and mean quadriceps tendon insertion thickness $6.5 \pm 1 \mathrm{~mm}(3.9-8.1 \mathrm{~mm})$. The correlation between patellar length and thickness was 0.70 , but a low correlation was observed between tendon thickness and patellar diameter (Table 1). Templating the modified tension band technique on the MRI slide indicated that all Kirschner wiring has to pass through tendinous soft tissue.

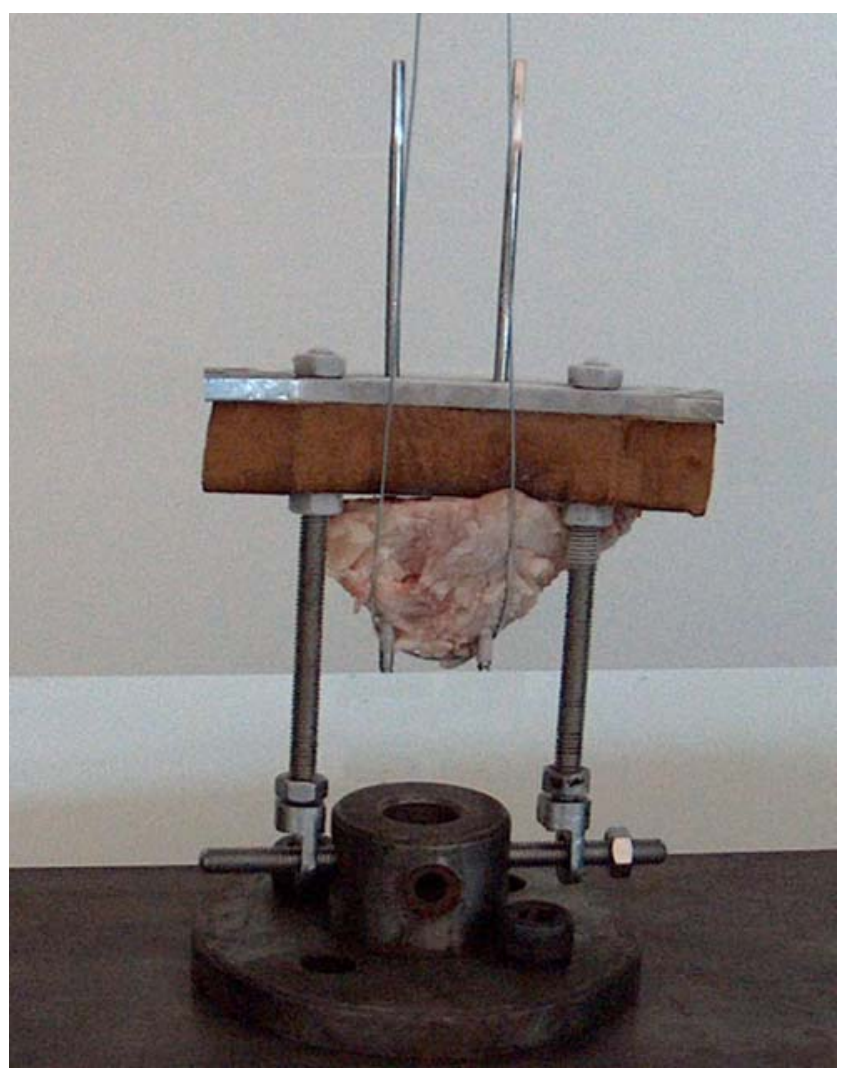

Fig. 4 Photograph showing application of the cyclic loading tendon (c) and to eliminate the effect of the tendon a control group (d) was established as vertically oriented figure-of-eight without tendinous tissue

Biomechanical study results are shown in Table 2. At the first $200 \mathrm{~N}$ loading, the mean displacement in method 1 was $0.23 \mathrm{~mm}$ (SD: 0.07), in method 2 it was $0.16 \mathrm{~mm}$ (SD: 0.14 ), in method 3 it was $0.23 \mathrm{~mm}$ (SD: 0.06) and in method 4 it was $0.14 \mathrm{~mm}$ (SD: 0.04). The mean displacement after the cyclic loading test in method 1 was $0.89 \mathrm{~mm}$ (SD: 0.31), in method 2 it was $0.57 \mathrm{~mm}$ (SD: 0.17 ), in method 3 it was $0.46 \mathrm{~mm}$ (SD: 0.11 ) and in method 4 it was $0.29 \mathrm{~mm}$ (SD: 0.09).

The results indicate that there was a significant difference between all groups compared with the Kruskal-Wallis test $(p=0.000)$. Using the Mann-Whitney test, there was a significant difference between group 1 and group $2(p=$ 0.012 ), group 1 and group 3 ( $p=0.04$ ), group 1 and group 4 $(p=0.02)$ and group 2 and group $4(p=0.02)$.

\section{Discussion}

The concept of more rigid fixation in patellar fractures is controversial. Yet there are high complication rates with the tension band technique and early mobilisation requires more rigid fixation methods.

Several biomechanical studies and several modifications of the tension band technique indicate that the relationship between the tension band and soft tissue around the patella affect stability in treatment of patellar fractures [1-10]. The tension band technique is important for patellar fractures; yet these techniques are more functional in the knee flexion position. Horizontally oriented figure-of-eight for tension band configuration is found to be stronger than the vertically oriented ones, which our test results support [6]. Improved wire twisting and flexible tension band material are helpful for good force distribution, thus decreasing failure rate $[6,8]$. Other techniques are effective in the knee extension position, 
Table 1 MRI results for 30 patellae: patellar length $(P L)$, patellar thickness $(P T)$, quadriceps tendon thickness $(Q T t)$, patellar tendon thickness $(P T t)$ and correlation between them

\begin{tabular}{|c|c|c|c|c|c|c|c|}
\hline & PL & PT & QTt & $\mathrm{PTt}$ & $\mathrm{PL} / \mathrm{PT}$ & $\mathrm{PTt} / \mathrm{PT}$ & QTt/PT \\
\hline 1 & 34.5 & 21.6 & 5.7 & 4.8 & 1.597222 & 0.222222 & 0.263889 \\
\hline 2 & 35.2 & 19.4 & 6.8 & 5.9 & 1.814433 & 0.304124 & 0.350515 \\
\hline 3 & 37.9 & 18.9 & 3.9 & 3.3 & 2.005291 & 0.174603 & 0.206349 \\
\hline 4 & 36.6 & 22.9 & 6.8 & 5.7 & 1.598253 & 0.248908 & 0.296943 \\
\hline 5 & 35.6 & 20.3 & 6.7 & 3.3 & 1.753695 & 0.162562 & 0.330049 \\
\hline 6 & 35.2 & 16 & 6 & 4.5 & 2.2 & 0.28125 & 0.375 \\
\hline 7 & 33.9 & 18 & 6.9 & 5.4 & 1.883333 & 0.3 & 0.383333 \\
\hline 8 & 33.9 & 19.2 & 6.8 & 6.1 & 1.765625 & 0.317708 & 0.354167 \\
\hline 9 & 42.9 & 26.1 & 8 & 6.8 & 1.643678 & 0.260536 & 0.306513 \\
\hline 10 & 35.2 & 17.1 & 5.8 & 4.7 & 2.05848 & 0.274854 & 0.339181 \\
\hline 11 & 31.8 & 17.6 & 6.9 & 3.9 & 1.806818 & 0.221591 & 0.392045 \\
\hline 12 & 31.7 & 20 & 5.4 & 5.7 & 1.585 & 0.285 & 0.27 \\
\hline 13 & 30.6 & 16.2 & 6.3 & 3.9 & 1.888889 & 0.240741 & 0.388889 \\
\hline 14 & 31 & 15.5 & 8.1 & 4.8 & 2 & 0.309677 & 0.522581 \\
\hline 15 & 38.8 & 22.8 & 5.9 & 3.6 & 1.701754 & 0.157895 & 0.258772 \\
\hline 16 & 33.5 & 20.8 & 8.1 & 6 & 1.610577 & 0.288462 & 0.389423 \\
\hline 17 & 33.9 & 19.3 & 4.3 & 3.6 & 1.756477 & 0.186528 & 0.222798 \\
\hline 18 & 37.5 & 19.7 & 6.8 & 5.7 & 1.903553 & 0.28934 & 0.345178 \\
\hline 19 & 40.3 & 20.3 & 5.7 & 4.8 & 1.985222 & 0.236453 & 0.280788 \\
\hline 20 & 39.9 & 23.6 & 5.5 & 5.5 & 1.690678 & 0.233051 & 0.233051 \\
\hline 21 & 32.8 & 19 & 6.8 & 4.3 & 1.726316 & 0.226316 & 0.357895 \\
\hline 22 & 30.6 & 17.6 & 6.5 & 3 & 1.738636 & 0.170455 & 0.369318 \\
\hline 23 & 31.4 & 19.5 & 7.6 & 5.4 & 1.610256 & 0.276923 & 0.389744 \\
\hline 24 & 33.2 & 19.5 & 6.8 & 4.7 & 1.702564 & 0.241026 & 0.348718 \\
\hline 25 & 34.6 & 19.5 & 7.2 & 6.5 & 1.774359 & 0.333333 & 0.369231 \\
\hline 26 & 33.9 & 19.7 & 6.8 & 4.8 & 1.720812 & 0.243655 & 0.345178 \\
\hline 27 & 33.6 & 20.5 & 7.8 & 6.3 & 1.639024 & 0.307317 & 0.380488 \\
\hline 28 & 35.3 & 19.9 & 7.2 & 4.2 & 1.773869 & 0.211055 & 0.361809 \\
\hline 29 & 33.9 & 17.9 & 6.5 & 4.5 & 1.893855 & 0.251397 & 0.363128 \\
\hline 30 & 31.9 & 19.4 & 5.1 & 3.6 & 1.64433 & 0.185567 & 0.262887 \\
\hline Mean & 34.70333 & 19.59333 & 6.49 & 4.843333 & 1.782433 & 0.248085 & 0.335262 \\
\hline Standard deviation & 3.001549 & 2.267603 & 1.024308 & 1.0431 & 0.15495 & 0.049492 & 0.065327 \\
\hline Correlation & & & & & 0.696617 & 0.397679 & 0.061432 \\
\hline
\end{tabular}

but their combination with the tension band technique is best and most effective in any position $[2,3]$.

According to the templating study of the tension band technique on the MRI section, the Kirschner wire must pass

Table 2 Tension band cyclic loading test results

\begin{tabular}{lll}
\hline Tension band method & First displacement & Total displacement \\
\hline A & $0.230 \pm 0.070$ & $0.893 \pm 0.313$ \\
B & $0.228 \pm 0.056$ & $0.461 \pm 0.114$ \\
C & $0.164 \pm 0.138$ & $0.572 \pm 0.170$ \\
D & $0.141 \pm 0.041$ & $0.275 \pm 0.086$ \\
\hline
\end{tabular}

Tension band configurations are vertically oriented figure-of-eight passing anteriorly to tendon (A), horizontally oriented figure-ofeight passing anteriorly to tendon (B), vertically oriented figure-ofeight passing posteriorly to tendon (C) and vertically oriented figure-of-eight without soft tissue (D). First displacement shows value is $200 \mathrm{~N}$ initial traction. Total displacement shows total displacement after ten cyclic loadings through tendinous tissue and tension band material must turn over this soft tissue. Our anatomical study shows that there is no statistical correlation between patellar length and thickness to confirm similar knowledge in the literature.

It is a fact that the expected result of the tension band techniques is affected by many factors such as variety of patellae, surgical practice and traumatic damage. But the Kirschner wire end point is placed deeply in some practices so that more interposed tendinous tissue can diminish stability. Many treatment methods are discussed in the literature with clinical results and biomechanical studies, and numerous results indicate the importance of the relationship between tension band and soft tissue.

For the biomechanical study, we used cow patellae because fresh tendinous attachment was needed as test material. The cow patella is too big to correlate with a human patella so a biomechanical test was designed to use only one part of the cow patella. The pole part of the cow patella with tendinous 
insertion was prepared similar in length to a human patellar fragment. The test was performed on one part of the patella only to eliminate practical error, as we were only interested in the tension band and soft tissue relationship.

In our study, we preferred cyclic loading test at 100-200 $\mathrm{N}$ because loading at over $200 \mathrm{~N}$ causes Kirschner wire bending. If this test were repeated in the flexion position, the Kirschner wire could not bend so we could reach a physiological loading force. Besides this, compression on the tension band is initially too high to prevent the progressive instability resulting in loss of reduction and angulation deformities. In our study, the tension band adjacent to bone surface had more stability than the tension band technique turned over tendinous tissue, but cyclic loading tests have shown that all tension band applications in this study lost their initial stability.

\section{Conclusions}

In conclusion, it is well known that the tension band is the main stability factor in patellar fractures in flexion. More stability and durability can be achieved in patellar fracture treatment, by transferring the tension force directly on to bone or at least choosing material that protects the tendon.

Open Access This article is distributed under the terms of the Creative Commons Attribution Noncommercial License which permits any noncommercial use, distribution, and reproduction in any medium, provided the original author(s) and source are credited.

\section{References}

1. Benjamin J, Bried J, Dohm M, McMurtry M (1987) Biomechanical evaluation of various forms of fixation of transverse patellar fractures. J Orthop Trauma 1:219-222

2. Berg EE (1997) Open reduction internal fixation of displaced transverse patella fractures with figure-eight wiring through parallel cannulated compression screws. J Orthop Trauma 11:573-576

3. Burvant JG, Thomas KA, Alexander R, Harris MB (1994) Evaluation of methods of internal fixation of transverse patella fractures: a biomechanical study. J Orthop Trauma 8:147-153

4. Carpenter JE, Kasman RA, Patel N, Lee ML, Goldstein SA (1997) Biomechanical evaluation of current patella fracture fixation techniques. J Orthop Trauma 11:351-356

5. Curtis MJ (1990) Internal fixation for fractures of the patella. A comparison of two methods. J Bone Joint Surg Br 72:280 282

6. John J, Wagner WW, Kuiper JH (2007) Tension-band wiring of transverse fractures of patella. The effect of site of wire twists and orientation of stainless steel wire loop: a biomechanical investigation. Int Orthop 31:703-707

7. Labitzke R (1997) Proper and improper tension band fixation exemplified by patellar fracture (in German). Chirurg 68:638642

8. Scilaris TA, Grantham JL, Prayson MJ, Marshall MP, Hamilton JJ, Williams JL (1998) Biomechanical comparison of fixation methods in transverse patella fractures. J Orthop Trauma 12:356359

9. Smith ST, Cramer KE, Karges DE, Watson JT, Moed BR (1997) Early complications in the operative treatment of patella fractures. J Orthop Trauma 11:183-187

10. Weber MJ, Janecki CJ, McLeod P, Nelson CL, Thompson JA (1980) Efficacy of various forms of fixation of transverse fractures of the patella. J Bone Joint Surg Am 62:215-220 